\title{
Efeitos do espaço de alojamento e da idade sobre desenvolvimento, integridade e proteção da mucosa intestinal de frangos de corte
}

\author{
[Effects of enclosure size and age on development, integrity and protection of the intestinal \\ mucosa in broiler chickens] \\ M. Thimotheo, M.F.R. Alves, F.R. Abe, I.C. Boleli* \\ Faculdade de Ciências Agrárias e Veterinárias - UNESP - Jaboticabal, SP \\ RESUMO
}

\begin{abstract}
Foi avaliado se o espaço de alojamento influencia o desenvolvimento da mucosa do intestino delgado de frangos, sendo usado um esquema fatorial 4 × $2\left(14,28,42,55\right.$ dias de idade e alojamento pequeno: $0,11 \mathrm{~m}^{2} /$ ave e grande: $0,525 \mathrm{~m}^{2} /$ ave). Foram analisadas: altura, perímetro e número dos vilos, profundidade das criptas, número de células caliciformes e número de vilos sem e com perda de epitélio e exposição do conjuntivo. Em ambos os espaços de alojamento, o número de vilos diminuiu e a profundidade das criptas aumentou com a idade nas três regiões intestinais. A altura e o perímetro dos vilos aumentaram de 14 para 28 dias no jejuno e íleo, e o número de células caliciformes foi maior no duodeno e íleo a partir dos 42 dias. A perda de epitélio pelos vilos do íleo aumentou com a idade. Nas aves do alojamento grande, ocorreu aumento na altura e no perímetro dos vilos duodenais com a idade, possibilitado pelo aumento na profundidade das criptas, que resultou em vilos maiores nessas aves do que nas do alojamento pequeno aos 55 dias de idade. O número de células caliciformes diminuiu nas aves do alojamento pequeno aos 42 dias de idade. Os dados mostram que o tamanho do alojamento interferiu no modelo de desenvolvimento temporal da mucosa intestinal e que frangos apresentaram maior tamanho de vilo duodenal quando alojados em espaço maior.
\end{abstract}

Palavras-chave: célula caliciforme, espaço de alojamento, frango de corte, intestino, perda de epitélio, vilos

\begin{abstract}
This study evaluated if enclosure size and age influence the intestinal mucosa development of broiler chickens, using an experimental design in an 4x2 factorial arrangement $(14,18,42$ and 55 days of age and two enclosure spaces: small $=0.11 \mathrm{~m}^{2} /$ bird and large $\left.=0.525 \mathrm{~m}^{2} / \mathrm{bird}\right)$. Villous height, perimeter and number, and crypt depth, goblet cells number, and number of villous without and with epithelium loss and conjunctive tissue exposition were analyzed in duodenum, jejunum and ileum. Regardless of enclosure size, the villous number diminished and the crypt depth increased with the age in the three intestinal regions. From 14 to 28 days of age, villous height and perimeter increased in the jejunum and ileum. The number of goblet cells was greater from 42 days in duodenum and ileum, and epithelium loss increased until 42 days in the ileum. Broilers housed in small and large enclosures differed in the intestinal characteristics from 42 days. In broilers housed in large enclosure, duodenal villous height and perimeter increased with the age, with an increase in the crypt depth, reaching greater size at 55 days of age than duodenal villous of the broilers housed in a small enclosure. These later presented at 42 days a smaller number of goblet cells than the former. According these results, enclosure size influenced the temporal pattern of the intestinal mucosa development, and broilers presented major duodenal villous growth when housed in large enclosures.
\end{abstract}

Keywords: broiler chicken, goblet cell, epithelium loss, intestine, space of housing, villus

\section{INTRODUÇÃO}

O intestino delgado responde pela digestão final dos componentes da ração e absorção dos

Recebido em 12 de agosto de 2011

Aceito em 10 de agosto de 2012

Autor para correspondência (corresponding author)

E-mail: icboleli@fcav.unesp.br nutrientes estruturais e energéticos necessários para a manutenção e o crescimento das aves. Essas funções são realizadas por enterócitos, células do tecido epitelial que reveste sua superfície luminal. A proteção do epitélio contra 
efeitos abrasivos da digesta, pH e ação de enteropatógenos é realizada por camada de muco (glicoproteínas), secretado sobre sua superfície por suas células caliciformes, a qual também atua como barreira seletiva para os nutrientes a serem absorvidos e sítio de ligação para a microbiota intestinal (Boleli et al., 2008). O epitélio intestinal é um tecido altamente ativo, o que exige renovação celular constante (Maiorka et al., 2008), possibilitada pela proliferação de células indiferenciadas nas glândulas de Lieberkühn, cujas células-filhas adquirem as características fenotípicas de enterócitos, células caliciformes ou células enteroendócrinas (Cheng e Leblond, 1974).

O desenvolvimento pós-eclosão do intestino delgado envolve aumento na altura de seus vilos e, consequentemente, no número de enterócitos, células caliciformes e células enteroendócrinas (Imondi e Bird, 1966; Baranyiova, 1972; Baranyiova e Holman, 1976; Maiorka et al., 2008).

A não preservação da integridade da mucosa intestinal das aves compromete a absorção de nutrientes (Noy e Sklan, 1995), alterando o desempenho das aves, podendo gerar perdas econômicas. Cerca de 23 a $38 \%$ da energia e proteína total absorvidas são utilizadas na manutenção do sistema digestório (Goodeeris, 2002). Assim, aumento dos gastos nutricionais e energéticos com a manutenção da mucosa intestinal reduz a disponibilidade deles para o desenvolvimento da massa muscular. O intestino delgado apresenta grande plasticidade de resposta à qualidade e quantidade de dieta ingerida pela ave, o que possibilita a influência de seu desenvolvimento pela digesta. O bemestar animal, no que se refere ao espaço de confinamento e à densidade, também pode influenciar o desenvolvimento e a manutenção do intestino delgado, por interferir na atividade dos animais e no consumo de água e alimento (Paranhos da Costa, 2002).

Diante disso, o presente trabalho comparou o desenvolvimento da mucosa intestinal de frangos mantidos em dois diferentes espaços de confinamento até os 55 dias de idade, mantendose o tamanho do grupo.

\section{MATERIAL E MÉTODOS}

O protocolo experimental do presente estudo foi aprovado pela Comissão de Ética no Uso de Animais (CEUA - protocolo n ${ }^{\circ}$ 023304/09), da Faculdade de Ciências Agrárias e Veterinárias, Universidade Estadual Paulista-Unesp, Campus de Jaboticabal.

Duzentos pintos de corte (Cobb®), com um dia de idade, foram distribuídos homogeneamente pelo peso corporal em boxes de dois tamanhos diferentes: 1,5 x 3,5m - espaço grande de alojamento (EG), com 10 aves/box e $0,525 \mathrm{~m}^{2}$ /ave -, e $0,75 \times 1,5 \mathrm{~m}$ - espaço pequeno de alojamento (EP) com 10 aves/box e $0,11 \mathrm{~m}^{2} /$ ave - , totalizando 10 repetições/espaço de alojamento. Adicionalmente, 60 aves, com peso similar às anteriores, foram mantidas para serem utilizadas na reposição das ave utilizadas nas analises em caso de mortalidade, mantendose o tamanho do grupo -10 aves/box. Tais aves receberam anilhas, para que não fossem utilizadas nas amostras das idades seguintes. As aves foram alojadas em boxes forrados com palha de arroz, em galpão de alvenaria, e receberam água e ração ad libitum. Foi utilizado sistema de alimentação com duas rações comerciais: ração inicial - um a 21 dias; $21 \%$ de PB e $2950 \mathrm{kcal} / \mathrm{kg}$ EM - e de crescimento - 22 a 55 dias; $18 \%$ de PB e $2800 \mathrm{kcal} / \mathrm{kg} \mathrm{EM} \mathrm{-,} \mathrm{à} \mathrm{base}$ de farelo de arroz, milho integral moído, farelo de trigo e de soja. As aves foram mantidas com $24 \mathrm{~h}$ de luz até os 14 dias e sob regime claro:escuro de $22 \mathrm{~h}: 2 \mathrm{~h}$ a partir dos 15 dias. Elas foram vacinadas para Gumboro e Newcastle. A temperatura e a umidade relativa do ar dentro do galpão apresentaram médias semanais de $28,8^{\circ} \mathrm{C}$, $26,7^{\circ} \mathrm{C}, 32,3^{\circ} \mathrm{C}, 27,1^{\circ} \mathrm{C}, 25,6^{\circ} \mathrm{C}, 26,3^{\circ} \mathrm{C}, 24,1^{\circ} \mathrm{C}$, $23,0^{\circ} \mathrm{C}$ e de $44,1 \%, 48,3 \%, 43,4 \%, 50,0 \%$, $62,6 \%, 63,4 \%, 74,0 \%$ e $78,3 \%$ da primeira à oitava semana, respectivamente. Aos 14, 28, 42 e 55 dias de idade, cinco aves por espaço de alojamento - um ave/repetição foram sacrificadas por deslocamento cervical, para coleta de amostras $(3 \mathrm{~cm})$ do duodeno, jejuno e íleo. As amostras foram abertas longitudinalmente, estiradas, lavadas cuidadosamente com água destilada e fixadas imediatamente em Bouin. Após, elas foram desidratadas em série de concentração crescente de etanol, diafanizadas em xilol, infiltradas e incluídas em histosec. As amostras foram orientadas para secção longitudinal dos 
segmentos intestinais. Foram realizados cinco cortes semisseriados, com $7 \mu \mathrm{m}$ de espessura, por amostra, os quais foram corados com PAS e montados com Entellan.

As seguintes variáveis foram analisadas: altura $(\mathrm{AV})$, perímetro $(\mathrm{PV})$ e número $(\mathrm{NV})$ de vilo, profundidade de cripta (PC), taxa de integridade dos vilos (PVN e PVE) e número de células caliciformes PAS positivas (NCC-PAS+) do duodeno, jejuno e íleo. A AV $(\mu \mathrm{m})$ correspondeu à distância entre sua base e seu ápice, e o PV $(\mu \mathrm{m})$ à medida do contorno de sua superfície. $\mathrm{O}$ $\mathrm{NV}$ correspondeu ao número de vilos presentes ao longo de $1686 \mu \mathrm{m}$ de cortes histológicos. A $\mathrm{PC}$ correspondeu à distância entre sua base e a base do vilo. O NCC-PAS+ foi obtido como o número de células presentes ao longo de $194 \mu \mathrm{m}$ de epitélio de cada vilo analisado. A integridade dos vilos foi analisada de acordo com os graus de perda de epitélio estabelecidos por Gomide Jr. et al. (2004). Os dados foram apresentados como porcentagens de vilos sem (PVN) e com (PVE) perda de epitélio e exposição de tecido conjuntivo. Eles foram obtidos a partir da análise dos vilos presentes ao longo de $1686 \mu \mathrm{m}$ de cortes histológicos da parede de cada região intestinal e de cada ave. $\mathrm{O}$ experimento seguiu um fatorial $2 \times 4$ (espaço pequeno e grande de alojamento e 14, 28, 42 e 55 dias de idade). Usou-se a análise de variância e, para a comparação entre médias, o teste de Tukey $(\mathrm{P} \leq 0,05)$, empregando-se o programa $\mathrm{SAS}^{\circledR}$ (2002)

\section{RESULTADOS}

Os dados referentes ao duodeno são mostrados nas Tab. 1 e 2. Houve interação significativa $(\mathrm{P} \leq 0,05)$ de espaço de alojamento versus idade para altura $(\mathrm{AV})$, perímetro $(\mathrm{PV})$ e número $(\mathrm{NV})$ de vilos. A AV permaneceu inalterada até os 55 dias nas aves do EP, mas aumentou de 14 para 28 dias, cujos valores foram mantidos até 55 dias, nas aves do EG. Aos 55 dias de idade, a AV foi maior nas aves do EG que nas do EP. Dados similares foram registrados para $\mathrm{PV}$, exceto nas aves do EG, em que o PV aumentou durante todo o período experimental. O NV nas aves do EP permaneceu inalterado de 14 para 28 dias, diminuiu de 28 para 42 dias, mantendo-se constante até 55 dias. Nas aves do EG, o NV diminuiu a partir dos 28 dias de idade. Aos 42 dias de idade, o NV foi maior nas aves do EG que nas do EP. A profundidade das criptas (PC) foi influenciada significativamente $(\mathrm{P} \leq 0,05)$ pelo espaço de alojamento e pela idade. A PC duodenal foi maior nos frangos do EG do que nos frangos do EP e aumentou de 14 para 42 dias, mantendo-se constante até 55 dias. O número de células caliciformes (NCC) foi influenciado significativamente $(\mathrm{P} \leq 0,05)$ apenas pela idade. O NCC foi constante até 28 dias, aumentou de 28 para 42 dias, mantendo-se inalterado até 55 dias de idade. As porcentagens de vilos sem (PVN) e de vilos com perda de epitélio e exposição do tecido conjuntivo (PVE) não foram afetadas significativamente $(\mathrm{P}>0,05)$ pelo espaço de alojamento e pela idade, e não houve interação entre os fatores.

Tabela 1. Altura (AV, $\mu \mathrm{m})$, perímetro $(\mathrm{PV}, \mu \mathrm{m})$, número de vilos $(\mathrm{NV})$, profundidade da cripta $(\mathrm{PC}, \mu \mathrm{m})$, número de células caliciformes (NCC), porcentagem de vilos normais (PVN), porcentagem de vilos com perda de epitélio e exposição de tecido conjuntivo (PVE) no duodeno de frangos de corte, segundo o espaço de alojamento e dias de idade

\begin{tabular}{lccccccc}
\hline & $\mathrm{AV}$ & $\mathrm{PV}$ & $\mathrm{NV}$ & $\mathrm{PC}$ & $\mathrm{NCC}$ & $\mathrm{PVN}$ & PVE \\
\hline Espaço pequeno & 1388,56 & 2992,20 & 9,45 & $261,11 \mathrm{~b}$ & 12,42 & 87,18 & 12,83 \\
Espaço grande & 1418,45 & 3064,00 & 9,91 & $309,46 \mathrm{a}$ & 12,25 & 84,91 & 15,09 \\
& & & & & & & \\
14 dias & 1166,08 & 2515,80 & 11,88 & $195,91 \mathrm{c}$ & $10,27 \mathrm{~b}$ & 86,52 & 13,48 \\
28 dias & 1426,82 & 3064,60 & 12,00 & $268,10 \mathrm{~b}$ & $10,89 \mathrm{~b}$ & 80,36 & 19,64 \\
42 dias & 1481,38 & 3170,40 & 8,82 & $335,06 \mathrm{a}$ & $13,40 \mathrm{a}$ & 84,99 & 15,01 \\
55 dias & 1549,01 & 3379,50 & 6,18 & $342,07 \mathrm{a}$ & $14,64 \mathrm{a}$ & 92,31 & 7,69 \\
\hline Probabilidade & & & & & & & \\
Espaço (E) & 0,6039 & 0,5515 & 0,0178 & 0,0020 & 0,8452 & 0,5342 & 0,5342 \\
Idade (I) & $<0,0001$ & $<0,0001$ & $<0,0001$ & $<0,0001$ & $<0,0001$ & 0,1545 & 0,1545 \\
E x I & 0,0316 & 0,0194 & 0,0002 & 0,2515 & 0,0542 & 0,8011 & 0,8011 \\
CV(\%) & 10,74 & 10,59 & 8,87 & 15,91 & 8,45 & 13,24 & 81,65 \\
\hline
\end{tabular}

Letras indicam diferenças significativas entre médias (colunas) pelo teste de Tukey $(\mathrm{P} \leq 0,05)$.

$\mathrm{CV}(\%)=$ coeficiente de variação da parcela. 
Efeitos do espaço de alojamento...

Tabela 2. Desdobramento da interação espaço de alojamento e idade (dias) para altura (AV, $\mu \mathrm{m})$, perímetro $(\mathrm{PV}, \mu \mathrm{m})$, número de vilos $(\mathrm{NV})$ no duodeno de frangos de corte

\begin{tabular}{lcccc}
\hline Variáveis & Idades & Espaço pequeno & Espaço grande & $\mathrm{P}$ \\
\hline $\mathrm{AV}$ & 14 & $1244,49 \mathrm{Aa}$ & $1087,67 \mathrm{Ab}$ & 0,1103 \\
& 28 & $1431,81 \mathrm{Aa}$ & $1421,83 \mathrm{Aa}$ & 0,9174 \\
& 42 & $1478,50 \mathrm{Aa}$ & $1483,68 \mathrm{Aa}$ & 0,9595 \\
& 55 & $1417,42 \mathrm{Ba}$ & $1680,60 \mathrm{Aa}$ & 0,0097 \\
\hline $\mathrm{PV}$ & 0,1088 & $<0,0001$ & \\
& 14 & $2661,97 \mathrm{Aa}$ & $2369,64 \mathrm{Ac}$ & 0,1598 \\
& 28 & $3094,56 \mathrm{Aa}$ & $3034,68 \mathrm{Ab}$ & 0,7699 \\
& 42 & $3187,59 \mathrm{Aa}$ & $3156,58 \mathrm{Aab}$ & 0,8864 \\
& 55 & $3063,84 \mathrm{Ba}$ & $3695,25 \mathrm{Aa}$ & 0,0040 \\
$\mathrm{NV}$ & $\mathrm{P}$ & 12,0768 & $<0,0001$ & \\
& 14 & $11,72 \mathrm{Aa}$ & $11,56 \mathrm{Aab}$ & 0,2482 \\
& 28 & $7,10 \mathrm{Bb}$ & $12,35 \mathrm{Aa}$ & 0,2831 \\
& 42 & $6,32 \mathrm{Ab}$ & $10,20 \mathrm{Ab}$ & $<0,0001$ \\
& 55 & $<0,0001$ & $6,04 \mathrm{Ac}$ & 0,6102 \\
\hline
\end{tabular}

Letras indicam diferenças significativas entre médias - minúsculas na coluna e maiúsculas na linha - pelo teste de Tukey $(\mathrm{P} \leq 0,05)$.

As Tab. 3 e 5 contêm os dados registrados para o jejuno. A AV, o PV, o NV e a PC jejunais foram influenciadas significativamente $(\mathrm{P} \leq 0,05)$ apenas pela idade. A AV e o PV aumentaram de 14 para 28 dias de idade, e permaneceram inalterados até os 55 dias de idade. O NV diminuiu de 14 para 28 dias de idade, cujos valores permaneceram inalterados até os 42 dias, e diminuiu entre 42 e 55 dias. A PC aumentou de 14 para 55 dias de idade. Quanto ao NCC, ocorreu interação significativa $(\mathrm{P} \leq 0,05)$ entre espaço de alojamento e idade. Nas aves do EG, esse parâmetro permaneceu inalterado com a idade. Nas aves do EP, o NCC aumentou de 42 para 55 dias de idade. Aos 42 dias, o NCC foi maior nas aves do EG que em EP. Para PVN e PVE não ocorreu efeito significativo do espaço de alojamento e da idade nem interação significativa $(\mathrm{P}>0,05)$ entre ambos.

Tabela 3. Altura $(\mathrm{AV}, \mu \mathrm{m})$, perímetro (PV, $\mu \mathrm{m})$, número de vilos $(\mathrm{NV})$, profundidade da cripta $(\mathrm{PC}, \mu \mathrm{m})$, número de células caliciformes (NCC), porcentagem de vilos normais (PVN), porcentagem de vilos com perda de epitélio e exposição de tecido conjuntivo (PVE) no jejuno de frangos de corte, segundo o espaço de alojamento e dias de idade

\begin{tabular}{|c|c|c|c|c|c|c|c|}
\hline & $\mathrm{AV}$ & PV & $\mathrm{NV}$ & $\mathrm{PC}$ & $\mathrm{NCC}$ & PVN & PVE \\
\hline $\begin{array}{l}\text { Espaço } \\
\text { pequeno }\end{array}$ & 904,50 & 1975,85 & 14,81 & 167,76 & 14,50 & 97,44 & 2,56 \\
\hline $\begin{array}{l}\text { Espaço } \\
\text { grande }\end{array}$ & 952,05 & 1997,42 & 14,70 & 178,68 & 14,56 & 97,21 & 2,71 \\
\hline 14 dias & $704,95 b$ & $1575,00 \mathrm{~b}$ & $18,05 \mathrm{a}$ & $151,17 \mathrm{~b}$ & 13,97 & 97,46 & 2,54 \\
\hline 28 dias & $998,37 \mathrm{a}$ & $2128,80 a$ & $15,40 \mathrm{~b}$ & $164,77 \mathrm{ab}$ & 14,94 & 97,44 & 2,56 \\
\hline 42 dias & $940,80 \mathrm{a}$ & $2037,40 a$ & $14,88 b$ & $179,91 \mathrm{ab}$ & 13,89 & 97,18 & 2,66 \\
\hline 55 dias & $1068,98 \mathrm{a}$ & $2228,40 \mathrm{a}$ & $10,70 \mathrm{c}$ & $200,26 a$ & 15,33 & 97,22 & 2,78 \\
\hline \multicolumn{8}{|l|}{ Probabilidade } \\
\hline Espaço (E) & 0,3246 & 0,6410 & 0,8745 & 0,3417 & 0,8744 & 0,8565 & 0,9051 \\
\hline Idade (I) & $<0,0001$ & $<0,0001$ & $<0,0001$ & 0,0466 & 0,0097 & 0,9976 & 0,9989 \\
\hline Ex I & 0,1109 & 0,0601 & 0,6133 & 0,1574 & 0,0160 & 0,1239 & 0,1234 \\
\hline $\mathrm{CV}(\%)$ & 16,19 & 14,34 & 14,19 & 20,28 & 7,30 & 3,99 & 14,29 \\
\hline
\end{tabular}

Letras indicam diferenças significativas entre médias (coluna) pelo teste de Tukey $(\mathrm{P} \leq 0,05)$.

$\mathrm{CV}(\%)=$ coeficiente de variação da parcela. 
Os dados obtidos para o íleo são mostrados nas Tab. 4 e 5. A AV, o PV, o NCC, a PVN e a PVE foram influenciados significativamente $(\mathrm{P} \leq 0,05)$ apenas pela idade. A AV e o PV aumentaram de 14 para 28 dias de idade, cujos valores foram mantidos inalterados até os 55 dias de idade. $\mathrm{O}$ NCC permaneceu inalterado até 28 dias, aumentou de 28 para 42 dias, mantendo-se novamente constante até 55 dias de idade. A PVN diminuiu e a PVE aumentou de 14 para 55 dias de idade. Houve interação significativa $(\mathrm{P} \leq 0,05)$ entre espaço de alojamento e idade para
NV e para PC. Nas aves do EP, o NV diminuiu de 14 para 28 dias, atingindo valores que foram mantidos até 55 dias. Nas aves do EG, o NV diminuiu de 14 para 42 dias, permanecendo inalterado de 42 para 55 dias. Aos 42 dias de idade, aves do EP apresentaram maior NV que as alojadas em EG. Quanto à PC, ela aumentou de 14 para 42 dias nas aves do EP, e de 28 para 55 dias de idade nas aves do EG. Aos 14 dias de idade, a PC foi maior nas aves do EG que nas do $\mathrm{EP}$, enquanto aos 42 e 55 dias ela foi maior nas aves do EP do que nas do EG.

Tabela 4. Altura $(\mathrm{AV}, \mu \mathrm{m})$, perímetro $(\mathrm{PV}, \mu \mathrm{m})$, número de vilos $(\mathrm{NV})$, profundidade da cripta $(\mathrm{PC}, \mu \mathrm{m})$, número de células caliciformes (NCC), porcentagem de vilos normais (PVN), porcentagem de vilos com perda de epitélio e exposição de tecido conjuntivo (PVE) no íleo de frangos de corte, segundo o espaço de alojamento e dias de idade

\begin{tabular}{lccccccc}
\hline & AV & PV & NV & PC & NCC & PVN & PVE \\
\hline Espaço pequeno & 702,29 & 1527,00 & 12,93 & 174,96 & 15,70 & 99,15 & 0,85 \\
Espaço grande & 744,30 & 1566,73 & 12,98 & 155,30 & 16,17 & 98,49 & 1,51 \\
& & & & & & & \\
14 dias & $525,89 \mathrm{~b}$ & $1132,30 \mathrm{~b}$ & 15,82 & 128,51 & $14,88 \mathrm{~b}$ & $99,85 \mathrm{a}$ & $0,15 \mathrm{~b}$ \\
28 dias & $735,99 \mathrm{a}$ & $1570,70 \mathrm{a}$ & 13,38 & 174,04 & $14,72 \mathrm{~b}$ & $98,18 \mathrm{ab}$ & $1,82 \mathrm{ab}$ \\
42 dias & $812,57 \mathrm{a}$ & $1745,40 \mathrm{a}$ & 11,22 & 190,03 & $17,51 \mathrm{a}$ & $99,60 \mathrm{ab}$ & $0,40 \mathrm{ab}$ \\
55 dias & $818,72 \mathrm{a}$ & $1782,70 \mathrm{a}$ & 11,24 & 203,83 & $16,63 \mathrm{a}$ & $97,66 \mathrm{~b}$ & $2,34 \mathrm{a}$ \\
\hline Probabilidade & & & & & & & \\
Espaço (E) & 0,1937 & 0,4392 & 0,6627 & 0,0130 & 0,1591 & 0,2137 & 0,2137 \\
Idade (I) & $<0,0001$ & $<0,0001$ & $<0,0001$ & $<0,0001$ & $<0,0001$ & 0,0123 & 0,0123 \\
E x I & 0,7145 & 0,7466 & 0,0386 & 0,0014 & 0,1224 & 0,4955 & 0,4955 \\
CV(\%) & 13,83 & 14,34 & 7,79 & 13,33 & 6,52 & 1,66 & 139,08 \\
\hline
\end{tabular}

Letras indicam diferenças significativas entre médias (coluna) pelo teste de Tukey $(\mathrm{P} \leq 0,05)$.

$\mathrm{CV}(\%)=$ coeficiente de variação da parcela.

Tabela 5. Desdobramento da interação entre espaço de alojamento (EP: espaço pequeno; EG: espaço grande) e idade (dias) para número de células caliciformes (NCC) no jejuno, e número de vilos (NV) e profundidade das criptas $(\mathrm{PC}, \mu \mathrm{m})$ no íleo de frangos de corte

\begin{tabular}{lccccc}
\hline $\begin{array}{c}\text { Segmento } \\
\text { intestinal }\end{array}$ & Variáveis & Idade & Espaço pequeno & Espaço grande & $\mathrm{P}$ \\
\hline Jejuno & $\mathrm{NCC}$ & 14 & $14,43 \mathrm{Aab}$ & $13,52 \mathrm{Aa}$ & 0,1866 \\
& 28 & $14,93 \mathrm{Aab}$ & $14,92 \mathrm{Aa}$ & 0,9882 \\
& 42 & $12,91 \mathrm{Bb}$ & $14,88 \mathrm{Aa}$ & 0,0061 \\
& 55 & $15,75 \mathrm{Aa}$ & $14,91 \mathrm{Aa}$ & 0,2199 \\
& $\mathrm{P}$ & 0,0017 & 0,1168 & \\
\hline Íleo & 14 & $15,40 \mathrm{Aa}$ & $16,24 \mathrm{Aa}$ & 0,1979 \\
& 28 & $12,88 \mathrm{Ab}$ & $13,88 \mathrm{Ab}$ & 0,1274 \\
& $\mathrm{NV}$ & $11,96 \mathrm{Ab}$ & $10,48 \mathrm{Bc}$ & 0,0272 \\
& & $11,12 \mathrm{Ab}$ & $11,34 \mathrm{Ac}$ & 0,7574 \\
& & $<0,0001$ & $<0,0001$ & 0,0332 \\
& $\mathrm{PC}$ & 14 & $112,86 \mathrm{Bc}$ & $144,15 \mathrm{Aab}$ & 0,2009 \\
& 28 & $155,65 \mathrm{Ab}$ & $136,23 \mathrm{Ab}$ & 0,0449 \\
& 42 & $204,69 \mathrm{Aa}$ & $175,36 \mathrm{Bab}$ & 0,0008 \\
\hline
\end{tabular}

Letras indicam diferenças significativas entre médias - minúsculas na coluna e maiúsculas na linha - pelo teste de Tukey $(\mathrm{P} \leq 0,05)$ 


\section{DISCUSSÃO}

Tamanho, número, integridade e proteção dos vilos, conjuntamente, determinam as áreas de digestão e absorção intestinais (Cera et al., 1988; Maiorka et al., 2008). Os três primeiros estão relacionados com a taxa de proliferação celular nas criptas e a taxa de extrusão celular na parte apical dos vilos, e o último com a produção de muco pelas células caliciformes.

Segundo Maiorka et al. (2001, 2008), o crescimento dos vilos ocorre quando a taxa de mitose é maior que a de extrusão ou quando não está ocorrendo extrusão, enquanto a manutenção de seus tamanhos é assegurada pelo equilíbrio entre perda e proliferação celular. A taxa de extrusão nos vilos duodenais, analisada no presente estudo pela PVN e PVE, foi similar em EG e EP e foi mantida constante até os 55 dias de idade em ambos os espaços de alojamento. Assim, o maior crescimento dos vilos duodenais nas aves do EG, bem como o crescimento temporal deles, deve ter sido resultante de maior proliferação celular, uma vez que a PC duodenal foi maior nas aves mantidas em EG. Os resultados deste trabalho assemelham-se aos obtidos por Uni et al. (1995) e Iji et al. (2001), que também observaram aumento na PC duodenal de frangos de corte com a idade. Segundo Boleli et al. (2008), o muco é constituído de glicoproteínas que formam uma barreira contra a ação enzimática, abrasão da passagem do bolo alimentar e da ação de enteropatógenos, bem como servem de sítios de ligação para a microbiota intestinal. Assim, a ausência de diferença na taxa de extrusão celular entre as aves do EP e do EG pode ter sido resultante da similaridade existente entre ambos em relação ao NCC.

No que se refere ao jejuno, os vilos aumentaram em altura até 28 dias idade e em largura até 55 dias, nas aves de ambos os espaços de alojamento. Considerando que a altura dos vilos é diretamente proporcional à área de absorção (Kisielinski et al., 2002), os resultados do presente estudo mostram que o espaço de alojamento não influenciou o desenvolvimento da mucosa jejunal e que as aves do EP e do EG apresentaram áreas similares de absorção jejunal durante todo o período experimental. É conhecido que crescimento dos vilos ocorre quando a taxa de mitose é maior que a de extrusão ou quando não está ocorrendo extrusão (Maiorka et al., 2001). Assim, a baixa e constante taxa de extrusão celular jejunal ao longo da idade, associada ao aumento concomitante da PC, deve responder pelo crescimento temporal dos vilos em ambos os espaços de alojamento. Os frangos do EG apresentaram NCC maior que os frangos do EP, mas apenas aos 42 dias de idade. Além disso, apenas nas aves do EP ocorreu aumento no NCC entre 42 e 55 dias, mas cujos valores foram similares aos apresentados até 28 dias. Tais dados mostram que as aves do EP apresentaram pontualmente uma menor proteção epitelial que as aves do EG aos 42 dias de idade, porém isso não resultou de aumento da extrusão celular jejunal, uma vez que não houve diferença no NVS entre as aves do EP e do EG.

Nas aves do EP, os vilos do íleo atingiram sua altura e largura máximas aos 28 dias de idade, enquanto nas aves do EG os vilos do íleo continuaram crescendo em largura até os 55 dias. Esse crescimento diferencial dos vilos do íleo entre aves alojadas em EP e EG parece explicar a diferença pontual observada entre elas no NV aos 42 dias. Quanto às criptas, elas tornaram-se mais profundas de 14 para 42 dias nas aves do EP e de 28 para 55 dias nas do EG, sendo menores nas aves do EG que nas do EP aos 42 e 55 dias. Tais diferenças na PC entre as aves do EP e EG parecem estar relacionadas com as diferenças registradas entre elas no crescimento dos vilos. De acordo com Pluske et al. (1997), maior valor de PC indica maior atividade proliferativa celular, para garantir adequada taxa de renovação epitelial, compensando as perdas nas alturas das vilosidades. De acordo com os resultados deste trabalho, o aumento na PC no íleo ocorreu simultaneamente com o aumento na taxa de extrusão celular, indicando, portanto, uma relação entre esses dois parâmetros. Segundo Robertis e Hib (2001), o muco produzido pelas células caliciformes protege o epitélio intestinal da ação de enzimas digestivas e de elementos agressivos como microrganismos ou parasitas que possam estar presentes no lúmen intestinal. No presente estudo, o NVE foi maior aos 55 dias do que aos 14 dias e o NCC foi maior a partir dos 42 dias, o que sugere que as aves responderam ao aumento de extrusão de células epiteliais com aumento no número de células que produzem o muco que protege a superfície do epitélio. 


\section{Thimotheo et al.}

\section{CONCLUSÕES}

Espaço de alojamento influencia o desenvolvimento temporal da mucosa intestinal dos frangos, e estes apresentam maior desenvolvimento e proteção intestinal quando alojados em espaço grande.

\section{AGRADECIMENTOS}

Os autores agradecem à Fundação de Amparo à Pesquisa do Estado de São Paulo (Fapesp, IC processo ${ }^{\circ}$ 2009/51710-2), pela bolsa concedida à MT.

\section{REFERÊNCIAS}

BARANYIOVA, E. Influence of deutectomy, food intake and fasting on the digestive tract dimensions in chickens after hatching. Acta Vet. Brno, v.41, p.373384, 1972.

BARANYIOVA, E.; HOLMAN, J. Morphological changes in the intestinal wall in fed and fasted chickens in the first week after hatching. Acta Vet. Brno, v.45, p.151-158, 1976.

BOLELI, I.C.; MAIORKA, A.; MACARI, M. Estrutura funcional do trato digestório. In: MACARI, M.; FURLAN, R.L.; GONZALES, E. (Eds). Fisiologia aviária aplicada a frangos de corte. Jaboticabal: FUNEP/UNESP, 2008. p.75-95.

CERA, K.R.; MAHAN, D.C.; CROSS, R.F. et al. Effect of age, weaning and post weaning diet on small intestinal growth and jejunal morphology in young suine. J. Anim. Sci., v.66, p.574-584, 1988.

CHENG, H.; LEBLOND, C.P. Origin, differentiation and renewal of the four main epithelial cells in the mouse small intestine. IV. Unitarian theory of the origin of the four epithelial cell types. Am. J. Anat., v.141, p.537-561, 1974.

GOMIDE Jr., M.H.; STERZO, E.V.; MACARI, M. et al. Use of Scanning Electron Microscopy for the Evaluation of Intestinal Epithelium Integrity. Rev. Bras. Zootec., v.33, p.1500-1505, 2004.

GOODEERIS, B.M.; BOERSMA,W.J.A.; COX, E. et al. Nutrition and health of the gastrointestinal tract. Paises Bajos: Poultry Wageningen Academic, 2002. p. 97-134.
IJI, P.A.; SAKI, A.; TIVEY, D.R. Body and intestinal growth of broiler chicks on a commercial starter diet. 1. Intestinal weight and mucosal development. $\mathrm{Br}$. Poult. Sci., v.42, p.505-513, 2001.

IMONDI, A.R.; BIRD, F.H. The turnover of intestinal epithelium in the chick. Poult. Sci., v.45, p.142-146, 1966.

KISIELINSKI, K.; WILLIS, S.; PRESCHER, A. et al. A simple new method to calculate small intestine absorptive surface in the rat. Clin. Exp. Med., v.2, p.131-135, 2002.

MAIORKA, A. Adaptações digestivas pós-eclosão. In: CONFERÊNCIA APINCO DE CIÊNCIA E TECNOLOGIA AVÍCOLAS, 2001, Campinas. Anais...Campinas: Fundação Apinco de Ciência e Tecnologia Avícolas, 2001. p.141-152.

MAIORKA, A.; BOLELI, I.C.; MACARI, M. Desenvolvimento e reparo da mucosa intestinal. In: MACARI, M.; FURLAN, R.L.; GONZALES, E. (Eds). Fisiologia aviária aplicada a frangos de corte. Jaboticabal: FUNEP/UNESP, 2008. p.113-124.

NOY, Y.; SKLAN, D. Digestion and absorption in the young chick. Poult. Sci., v.74, p.366-373, 1995.

PARANHOS DA COSTA, M.J.R Comportamento e bem-estar. In: MACARI, M.; FURLAN, R.L.; GONZALES, E. Fisiologia aviária aplicada a frangos de corte. Jaboticabal: FUNEP/UNESP, 2002. p.327345 .

PLUSKE, J.R.; HAMPSON, D.J.E.; WILLIAMS, I.H. Factors influencing the stricture and function of the small intestine en the weaned pig: a review. Livest. Prod. Sci., v.51, p.215-236, 1997.

ROBERTIS, E.M.F.; HIB, J. Bases da Biologia Celular e Molecular. 3.ed. Rio de Janeiro: Guanabara Koogan, 2001. 408p.

SAS Institute. 2002. SAS Proprietary Software Release 9.2. SAS Inst. Inc., Cary, NC.

UNI, Z.; NOY, Y.; SKLAN, D. Post-hatch changes in morphology and function of the small intestines in heavy and light strain chicks. Poult. Sci., v.74, p.1622$1629,1995$. 